\title{
The Effect of Joint Mobilization on the Expressions of Nadph-Diaphorase and Nitric Oxide Synthase in the Spinal Cord Neurons
}

\author{
Toshifumi Kuwaoka, HanSuk Jung*, JooHyun Ham, JinOk Choi, HyeRin Cho
}

Department of Chiropractic, Hanseo University, Seosan 31962, Korea

*Correspondence to: Jung $\mathrm{HS}$,

Tel: +82-41-660-1875

Fax: +82-41-660-1098

E-mail: hsjung@hanseo.ac.kr

Received May 22, 2015

Revised July 7, 2015

Accepted August 4, 2015

\begin{abstract}
The aim of this study was to investigate effects on joint mobilization in neurochemical changes of nicotinamide adenine dinucleotide phosphate-diaphorase (NADPH-d) and nitric oxide synthase (NOS) of the spinal cord neurons after right knee joint immobilization (RKJI) and in ultrastructural changes of the femoral nerves innervating the muscles acting on RKJI. A total of 15 guinea pigs were used and divided into 5 groups. Immunohistochemistry was performed to detect NADPH-d and NOS. NADPH-d and NOS were not expressed in the ventral horn of control and experimental groups, but were expressed or not in the dorsal horn according to the duration of release after RKJI and the presence or absence of joint mobilization. Ultrastructures of the femoral nerves in experimental groups had partial demyelination and condensed clumps in axon. Effects on manipulative therapy after RKJI were confirmed from expression of NADPH-d and NOS in the dorsal horn of the lumbosacral spinal cord. Manipulative therapy was more effective against a long-term immobilization than a short-term immobilization.
\end{abstract}

Key Words: Knee joint, Joint mobilization, Nicotinamide adenine dinucleotide phosphatediaphorase, Nitric oxide synthase, Immobilization

\section{INTRODUCTION}

Knee joint immobilization is common medical practice used to manage musculoskeletal injuries; however, immobilization of the knee joint for a period generally causes degenerative alterations in many articular tissues (He \& Dishman, 2009). Together with the articular tissues, neural tissue in the knee joint will also be altered after knee joint immobilization (Fuglsang-Frederiksen \& Scheel, 1978; Michinaka et al., 1997; Kanemura et al., 2002). Progressive degeneration of articular tissues by immobilization of the knee joint, especially longterm immobilization appears to result in the Knee joint problems. Knee joint problems are one of the most common ailments of the musculoskeletal system and can produce pain. Chiropractic manipulative therapy can be helpful in alleviating some of the pain in knee joint problems (Xiaohua et al., 2008), and are also effective on extremity conditions (Hoskins et al., 2001; Nelson et al., 2005). Recent interest in nicotinamide adenine dinucleotide phosphate-diaphorase (NADPH-d) and nitric oxide synthase (NOS) has been focused on its expression in motor neurons of the central nervous system (CNS) after peripheral nerve injury (Gonzalez et al., 1987; Lei et al., 1992; Wu \& Li, 1993; Hama \& Sagen, 1994; Wu et al., 1994; Hee et al., 1997). NADPH-d had been detected in a subpopulation of neurons in the CNS and myentric plexus (Bredt et al., 1990; Hee et al., 1997). NOS is an enzyme for generation of nitric oxide (NO) which is implicated in a multiplicity of biological functions (Vincent \& Hope, 1992; Pannu \& Singh, 2006). At the CNS, it is known that, low concentrations of NO promote neuronal survival and growth (Dimmeler \& Zeiher, 1999; Xiong et al., 1999), while high concentrations exert toxic effects and neuron death

(a) This is an open-access article distributed under the terms of the Creative Commons Attribution Non-Commercial License (http://creativecommons.org/licenses/by-nc/4.0) which permits unrestricted noncommercial use, distribution, and reproduction in any medium, provided the original work is properly cited.

Copyrights (c) 2015 by Korean Society of Microscopy 
(Bao \& Liu, 2002; Shibata \& Kobayashi, 2008). Several studies have demonstrated NO involvement in neurodegenerative disorder causing neurons death such as Parkinson's disease, Alzheimer's disease and amyotrophic lateral sclerosis (Good et al., 1998; Tabner et al., 2002; Ischiropoulos \& Beckman, 2003). The induction and up-regulation of NADPH-d and NOS have been suggested to be related to neuronal degeneration and to be resulted from right knee joint immobilization (RKJI) (Dawson et al., 1991; Li et al., 1993; Wu \& Li, 1993; Hee et al., 1997).

Many of studies on the knee joint, muscles acting on the knee joint, the nerve supply to the knee joint and neuroanatomical and neurophysiological changes as the result of the knee joint immobilization in the knee joint have been carried out in different species, including the rats, cats, monkeys, rabbits and humans (Fuglsang-Frederiksen \& Scheel, 1978; Kennedy et al., 1982; Dorn et al., 1991; Hildebrand et al., 1991; Lee et al., 1991; Dougherty et al., 1992; Gardner, 1995; Michinaka et al., 1997; Kanemura et al., 2002; He et al., 2009). However, studies on the effects of chiropractic manipulative therapy in the knee joint problems are rarely. The aim of the present study was to investigate effects on joint mobilization in neurochemical changes of NADPH-d and NOS of the spinal cord neurons after RKJI, in ultrastructural change of nerves innervating the muscles acting on the RKJI.

\section{MATERIALS AND METHODS}

\section{Animals}

This study was approved by Graduate School of Health Promotion, Hanseo University, South Korea. A total of 15 guinea pigs of both sexes weighing 350 to $450 \mathrm{~g}$ were used and divided into 5 groups; control, 2 weeks release and manipulative therapy after 8 weeks RKJI (8I-2M) group, 2 weeks release only after 8 weeks RKJI (8I-2N) group, 2 weeks release and manipulative therapy after 4 weeks RKJI (4I-2M) group, and 2 weeks release only after 4 weeks RKJI (4I-2N) group (Table 1). All experiments were carried out in accordance with the guidelines regarding the care and use of animals for experimental procedures established by National Institutes of Health. Every step was taken to minimized animals suffering and reduced the number of animals used.

Table 1. Numbers of used animals in each group

\begin{tabular}{cccccc}
\hline Group & Control & $8 \mathrm{I}-2 \mathrm{M}$ & $8 \mathrm{I}-2 \mathrm{~N}$ & $4 \mathrm{I}-2 \mathrm{M}$ & $4 \mathrm{I}-2 \mathrm{~N}$ \\
\hline Number & 3 & 3 & 3 & 3 & 3 \\
\hline
\end{tabular}

8I-2M, 2 weeks release and manipulative therapy after 8 weeks right knee joint immobilization (RKJI); 8I-2N, 2 weeks release only after 8 weeks RKJI; 4I-2M, 2 weeks release and manipulative therapy after 4 weeks RKJI; 4I-2N, 2 weeks release only after 4 weeks RKJI.

\section{Right Knee Joint Immobilization and Joint Mobilization}

The fur around the right knee joint was shaved before immobilization. Two padded plastic splints were placed on the medial and lateral sides of the knee joint and were fixed with tape around the limb. The right knee joint from the lower $1 / 3$ of thigh to the upper $1 / 3$ of the leg was fixed in an extended position $\left(150^{\circ}\right)$ with two splints. After RKJI, the foot skin color and movements of the knee and hip joints were observed. The knee joint of animals were immobilized for 4 weeks ( 2 groups) and 8 weeks ( 2 groups) and then released. Released one group had joint mobilization for 2 weeks and the other group left freely (Table 1). Joint mobilization was performed by repetitive operation including contraction and extension of the right knee joint. Released day 1 had 5 times joint mobilization $\left(5^{\circ}\right)$, released day 2 had 10 times $\left(10^{\circ}\right)$, day 3 had 15 times $\left(15^{\circ}\right)$, days 4 to 14 had 20 times joint mobilization $\left(20^{\circ}\right.$ to $\left.90^{\circ}\right)$.

\section{General Histological Methods}

Animals were anesthetized with ketamine $(0.2 \mathrm{~mL} / 100 \mathrm{~g}$, Yuhan, Korea) and perfused via the left ventricle with $0.9 \%$ saline $\left(4^{\circ} \mathrm{C}\right)$ followed by $4 \%$ paraformaldehyde $\left(4^{\circ} \mathrm{C}\right)$ in $0.1 \mathrm{M}$ phosphate buffer (PBS, pH 7.4) for 30 minutes. The lumbosacral spinal cords from L5 to S1 were removed and postfixed in the same fixative for 2 to 3 hours, then were stored overnight in $20 \%$ sucrose in $0.1 \mathrm{M} \mathrm{PBS}$ at $4^{\circ} \mathrm{C}$. The spinal cords were cut transversely to a thickness of $30 \mu \mathrm{m}$ in a cryostat. Sections were mounted on gelatin coated slides and dried at room temperature for NADPH-d histochemistry and NOS immunohistochemistry.

\section{NADPH-d Histochemistry}

Sections of the lumbosacral spinal cord for NADPH-d histochemistry were incubated at room temperature for 60 minutes in a solution containing $0.1 \mathrm{M}$ Tris- $\mathrm{HCl}$ buffer $(\mathrm{pH}$ 7.6), $1 \mathrm{mg} / \mathrm{mL} \beta$-NADPH (Lot 82H7010, $1.2 \mathrm{mM}$; Sigma, USA), $0.5 \mathrm{mg} / \mathrm{mL}$ nitroblue tetrazolium (Sigma), then washed in 0.1 M PBS (pH 7.4) and distilled water, and then were examined with a microscope.

\section{Nitric Oxide Synthase Immunohistochemistry}

Sections of the lumbosacral spinal cord for NOS immunohistochemistry were washed with PBS ( $\mathrm{pH} 7.4$ ) containing $0.2 \%$ Triton X-100 (Sigma) and placed in $0.3 \% \mathrm{H}_{2} \mathrm{O}_{2}$ for 20 minutes to block endogenous peroxidase activity. After 3 rinses in PBS, sections were placed in $10 \%$ normal goat serum in 0.1 M PBS ( $\mathrm{pH} 7.4$ ) for 1 hour. Sections were then incubated overnight at room temperature in rabbit polyclonal anti-bNOS (Chemicon, USA) at dilution 1:70. To detect the reaction product from antigen-antibody bindings, a biotinylated goat antirabbit secondary antibody and a standard ABC kit (Vector Laboratories, USA) were used. Diaminobenzidine 
tetrahydrochloride was used as the peroxidase substrate. The sections were washed with PBS for 3 times, and were examined with a microscope.

\section{Electron Microscope of Femoral Nerve}

Quadriceps was fixed in 2.5\% glutaraldehyde and 2\% paraformaldehyde in Millonig's PBS ( $\mathrm{pH}$ 7.4) for 2 hours. The tissues was post-fixed with $1.3 \%$ osmium tetroxide in the same buffer for 2 hours, dehydrated with a series of the graded ethyl alcohol and acetone, and embedded in epoxy resin. Blocks were trimmed and cut transversely to thickness of 60 to $90 \mathrm{~nm}$ by an ultramicrotome. Thin sections of 60 to $90 \mathrm{~nm}$ were double stained with uranyl acetate and lead citrate for observation of an electron microscope. All of the thin sections were examined with a JEOL 100S transmission electron microscope (JEOL, Japan).

\section{Measurement of Area of Femoral Muscular Fiber}

Sections for measurement of area in femoral muscular fibers were stained with $5 \%$ toluidine blue, washed with distilled water and then were examined with a microscope. Perfectly cross sectionalized 50 muscular fibers having round form were randomly selected and measured in area with Motic Image Plus 2.0 (Motic Ltd., Taiwan).

\section{Statistical Analysis}

Areas of 50 femoral muscular fibers in quadriceps were measured. All measured data was assessed by analysis of the Excel statistical package (Microsoft, USA). Student's t-test was used for the comparison of two groups $(\mathrm{p}<0.05)$. Values were represented as mean \pm standard deviation.

\section{RESULTS}

\section{Motor Behavior}

After RKJI, the foot skin color and swelling of the immobilized limbs were checked daily to ensure adequate blood supply and nerve integrity of the limbs. Since the knee joints were immobilized in extended position, activity of the immobilized knee was totally lost. Movements at the hip joint were retained. Although quantifiable data on spontaneous movements were not made, movement was clearly reduced or appeared totally lost in guinea pigs with RKJI. In released animals after 8 weeks and 4 weeks of immobilization, spontaneous movements were gradually regained during the first week and returned to normal in the second week.

\section{NADPH-d Histochemistry}

NADPH-d was not expressed in the ventral horn of the lumbosacral spinal cord of non-immobilization control and all experimental groups (data not shown). In the dorsal horn of the lumbosacral spinal cord, NADPH-d was expressed or not expressed according to the duration of release after RKJI and the presence or absence of joint mobilization (Fig. 1). In the dorsal horn of the lumbosacral spinal cord, NADPH-d labeled neurons was seen in the non-immobilization control (Fig. 1A) and 8I-2M group having 2 weeks release and joint
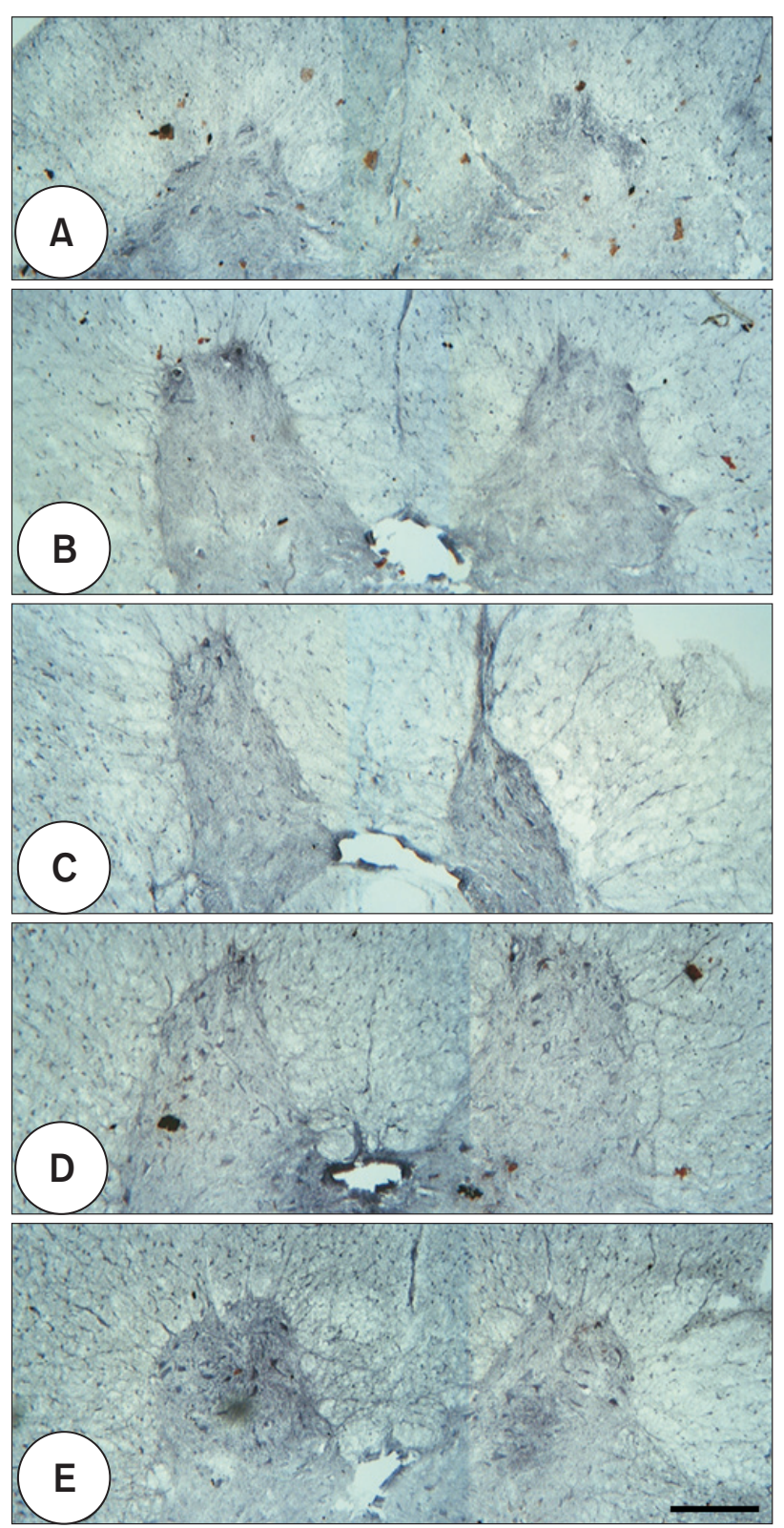

Fig. 1. Light micrographs showing histochemistry for nicotinamide adenine dinucleotide phosphate-diaphorase (NADPH-d) in the dorsal horn of the lumbosacral spinal cord. Nonspecific activity on NADPH-d labeled neurons is seen in the non-immobilization control (A) and 8I-2M group (B), low level activity is seen in the 8I-2N (C) and 4I-2M groups (D), and high level activity is seen in 4I-2N group (E). 8I-2M, 2 weeks release and joint mobilization after 8 weeks right knee joint immobilization (RKJI); 8I-2N, 2 weeks release only after 8 weeks RKJI; 4I-2M, 2 weeks release and joint mobilization after 4 weeks RKJI; 4I-2N, 2 weeks release only after 4 weeks RKJI. Scale bar $=100 \mu \mathrm{m}$. 

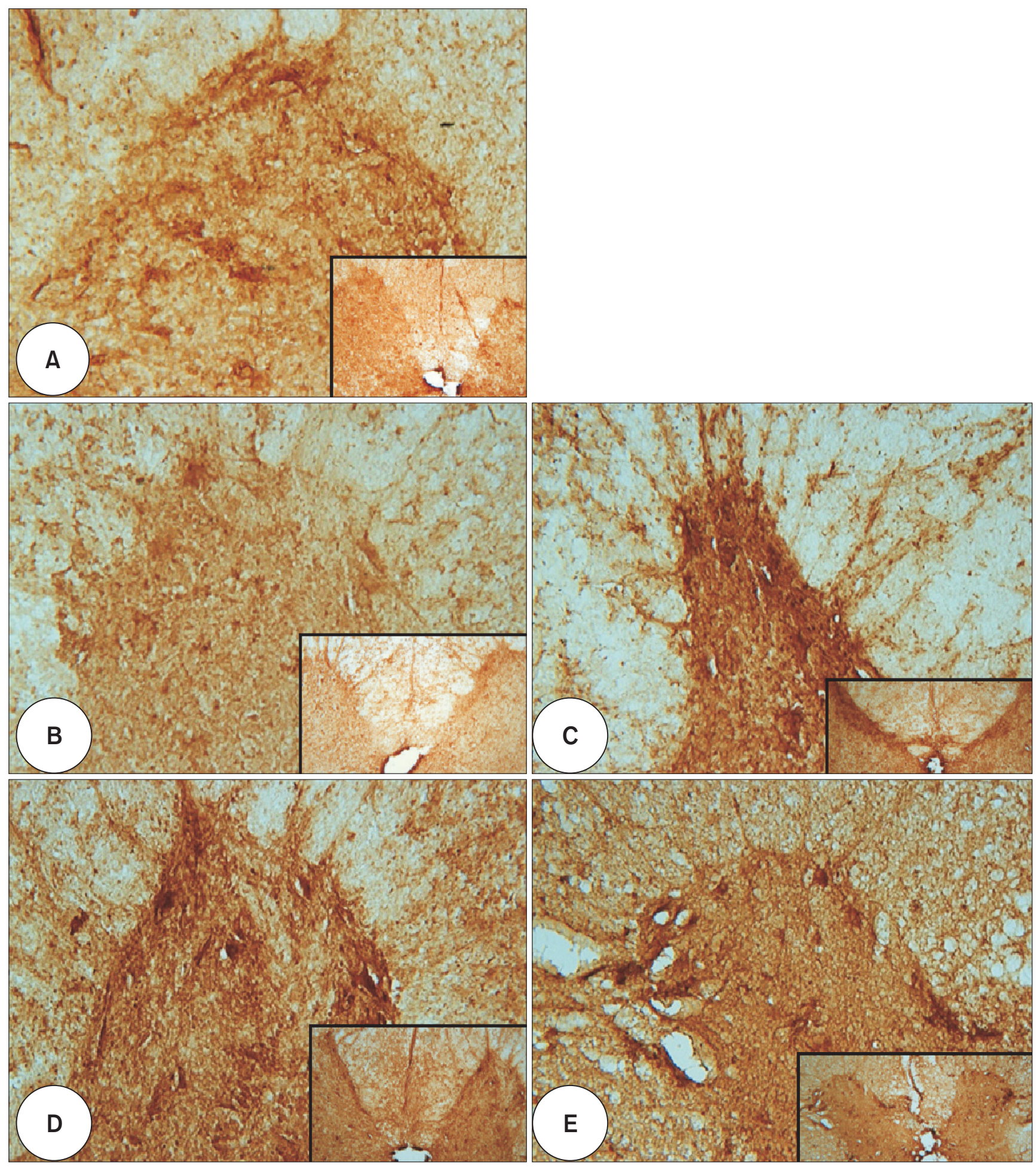

Fig. 2. High magnified micrographs showing immunohistochemistry for nitric oxide synthase (NOS) in the dorsal horn of the lumbosacral spinal cord. Nonspecific activity on NOS labeled neurons is seen in the non-immobilization control (A) and 8I-2M group (B), high level activity is seen in the 8I-2N group (C) and low level activity is seen in 4I-2M (D) and 4I-2N groups (E). Inset show low magnified image of the transverse section of the dorsal horn. 8I2M, 2 weeks release and joint mobilization after 8 weeks right knee joint immobilization (RKJI); 8I-2N, 2 weeks release only after 8 weeks RKJI; 4I-2M, 2 weeks release and joint mobilization after 4 weeks RKJI; 4I-2N, 2 weeks release only after 4 weeks RKJI. 

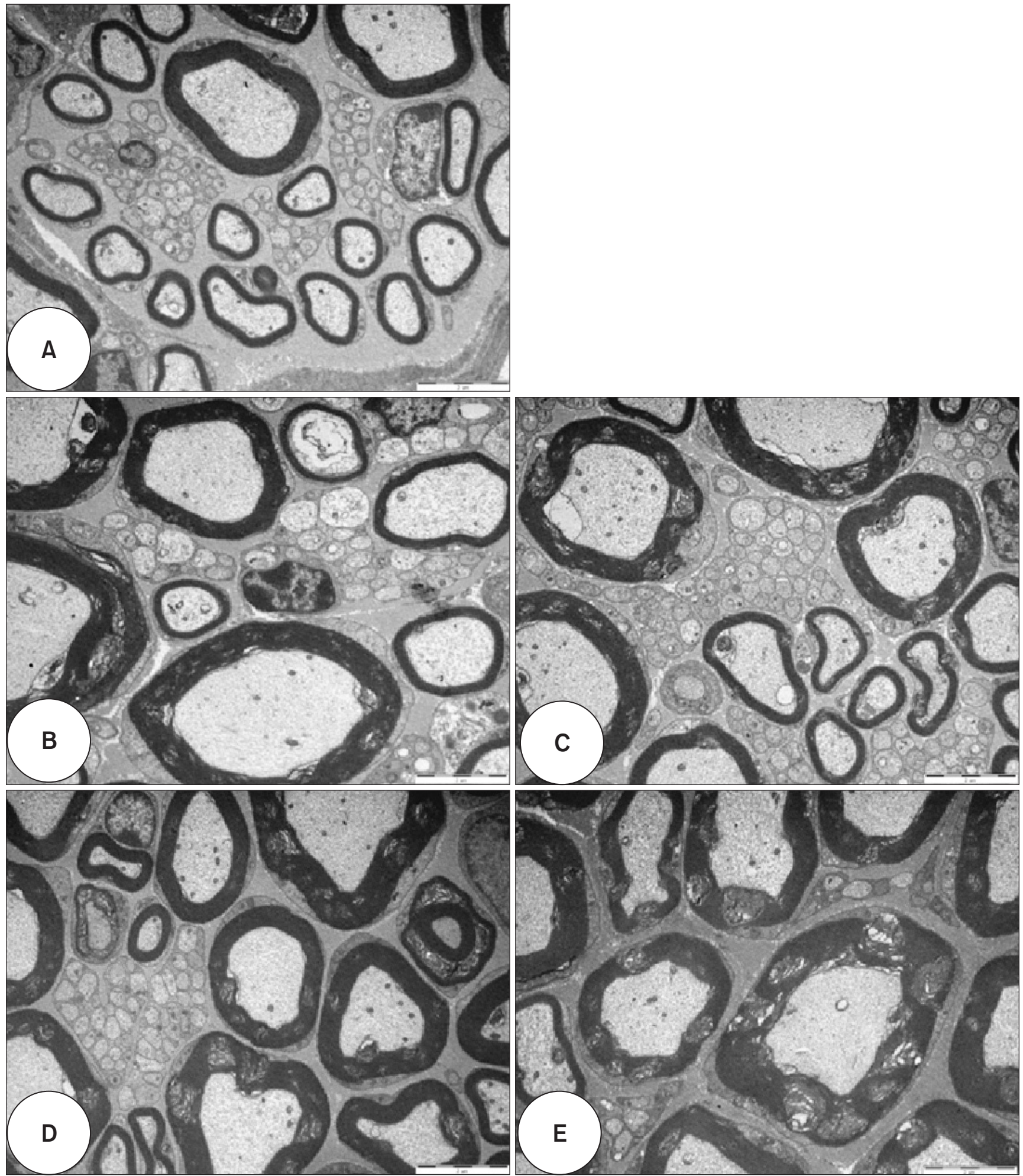

Fig. 3. Electron micrographs showing the femoral nerves. Sound axon and myelin sheath are seen in the non-immobilization control (A). Many of vacuoles and condensed clumps in axon and partial demyelination are seen in all experimental groups, 8I-2M (B), 8I-2N (C), 4I-2M (D), and 4I-2N (E). The extent of modification and morphologic characteristics in axon and myelin sheath are similar to all experimental groups. 8I-2M, 2 weeks release and joint mobilization after 8 weeks right knee joint immobilization (RKJI); 8I-2N, 2 weeks release only after 8 weeks RKJI; 4I-2M, 2 weeks release and joint mobilization after 4 weeks RKJI; 4I-2N, 2 weeks release only after 4 weeks RKJI. Scale bars $=2 \mu \mathrm{m}$. 
mobilization after 8 weeks RKJI (Fig. 1B), low level activity was seen in the $8 \mathrm{I}-2 \mathrm{~N}$ group having 2 weeks release only after 8 weeks RKJI (Fig. 1C) and 4I-2M group having 2 weeks release and joint mobilization after 4 weeks RKJI (Fig. 1D), and high level activity was seen in $4 \mathrm{I}-2 \mathrm{~N}$ group having 2 weeks release only after 4 weeks RKJI (Fig. 1E).

\section{Nitric Oxide Synthase Immunoreactivity}

NOS was not expressed in the ventral horn of the lumbosacral spinal cord of the non-immobilization control and all experimental groups as those of NADPH-d histochemistry (data not shown). In the dorsal horn of the lumbosacral spinal cord, NOS was expressed or not expressed according to the duration of release after RKJI and the presence or absence of joint mobilization (Fig. 2), but was distinguished from those of NADPH-d. In the dorsal horn of the lumbosacral spinal cord, NOS labeled neurons was seen in the nonimmobilization control (Fig. 2A) and 8I-2M group (Fig. 2B), High level activity was seen in 8I-2N group (Fig. 2C) and low level activity was seen in 4I-2M group (Fig. 2D) and 4I-2N group (Fig. 2E).

\section{Ultrastructures of Femoral Nerves}

Axon and myelin sheath of the femoral nerves in the nonimmobilization control and all experimental groups were observed (Fig. 3). Non-immobilization control had sound axon and myelin sheath (Fig. 3A), but the other experimental groups including 8I-2M (Fig. 3B), 8I-2N (Fig. 3C), 4I-2M (Fig. 3D), and 4I-2N (Fig. 3E) had modified axon and myelin

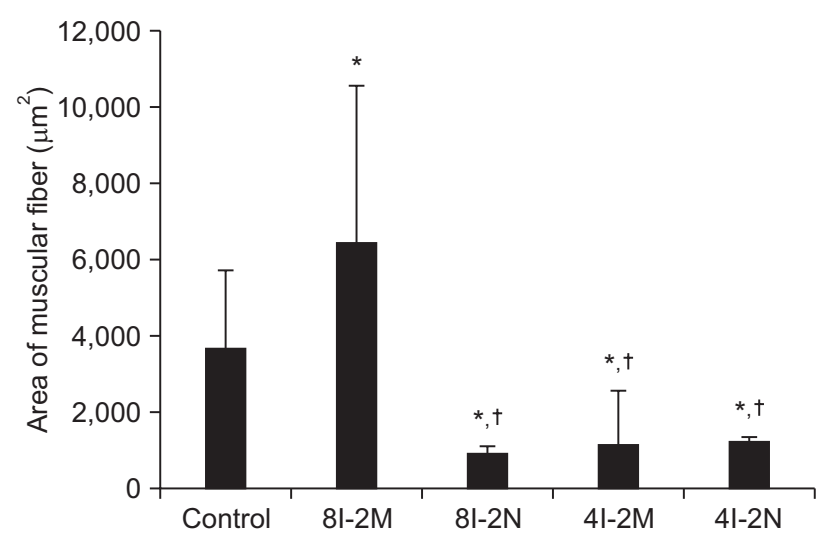

Fig. 4. Measurements of area of the muscular fibers in the quadriceps. Large measured values in area of the muscular fibers of 8I-2M group are not only distinguished from non-immobilization control but also the other experimental groups. Measured values in area of the muscular fibers of $8 \mathrm{I}-2 \mathrm{~N}, 4 \mathrm{I}-2 \mathrm{M}$, and $4 \mathrm{I}-2 \mathrm{~N}$ groups are similar to with each other. Data are mean \pm standard deviation $(n=50)$. 8I-2M, 2 weeks release and joint mobilization after 8 weeks right knee joint immobilization (RKJI); 8I-2N, 2 weeks release only after 8 weeks RKJI; 4I-2M, 2 weeks release and joint mobilization after 4 weeks RKJI; $4 \mathrm{I}-2 \mathrm{~N}, 2$ weeks release only after 4 weeks RKJI. * $\mathrm{p}<0.05$ compared to the non-immobilization control. ${ }^{\dagger} \mathrm{p}<0.05$ compared to the 8I-2M group. sheath, having many of vacuoles and condensed clumps in axon and partial demyelination. The extent of modification in axon and myelin sheath are similar to all experimental groups.

\section{Area of Femoral Muscular Fibers}

Femoral muscular fibers having round from in each group were randomly selected and measured in area. Measured value of 8I-2M group was significantly large and distinguished from those of the non-immobilization control and the other experimental groups $(\mathrm{p}<0.05)$. Measured value of $8 \mathrm{I}-2 \mathrm{~N}, 4 \mathrm{I}-$ $2 \mathrm{M}$, and $4 \mathrm{I}-2 \mathrm{~N}$ groups were similar to with each other and significantly smaller than the non-immobilization control (Fig. 4). Although measured value of 4I-2M group was not distinguished from those of 4I-2N group, measured value of 8I-2M group was not only distinguished from those of $8 \mathrm{I}-2 \mathrm{~N}$ group but also those of the non-immobilization control.

\section{DISCUSSION}

Changes of NADPH-d and NOS by joint mobilization and release after RKJI were examined in the ventral horn and the dorsal horn of the lumbosacral spinal cord.

Previous study showed that NADPH-d and NOS were expressed in the ventral horn of lumbosacral segments after RKJI (Hee et al., 1997). According to this study, under RKJI condition, expression of NADPH-d and NOS were progressive enhanced in the ventral horn and under release condition, $\mathrm{NADPH}-\mathrm{d}$ and NOS reactivity were prominently reduced in the ventral horn neurons. Also enhanced NADPH-d expression in the ventral horn motoneurons following peripheral nerve lesions has been reported (Gonzalez et al., 1987; Li et al., 1993; Wu et al., 1994). Present study showed that NADPH-d and NOS were not expressed in the ventral horn of the lumbosacral spinal cord regardless of the duration of release after RKJI and the presence of joint mobilization, however, NADPH-d and NOS were expressed or not expressed in the dorsal horn of the lumbosacral spinal cord according to the duration of release after RKJI and the presence or absence of joint mobilization. Also NADPH-d expression in the dorsal horn of the aged lumbosacral spinal cord under the non-stressed condition has been reported (Tan et al., 2006). Thus, it seems that such differences of the expressed regions are due to the released condition after RKJI, namely, NADPH-d and NOS are expressed in the ventral horn of the lumbosacral spinal cord under the stressed condition such as RKJI, while were expressed in the dorsal horn under the freely released condition.

NOS, an enzyme for generation of NO has 3 known isoforms of NOS, that is, the neuronal (nNOS), the endothelial (eNOS), and the inducible (iNOS) form, are found in nervous tissue (Bredt \& Snyder, 1992; Vincent \& Hope, 1992; Martin et al., 2005; Pannu \& Singh, 2006; Sung et al., 2010). The different 
NOS isoforms changed reciprocally during motor neurons apoptosis; nNOS protein was upregulated, whereas iNOS protein was downregulated. But, the residual iNOS contributes more than the upregulated nNOS to the injury-induced transient increase in NADPH-d activity and $\mathrm{NO}$ production (Martin et al., 2005). The iNOS has been found to be a major factor to initiation of the CNS inflammatory or degenerative conditions through the production of excessive NO (Pannu \& Singh, 2006). It has been well known that No generated by iNOS has both neuroprotective and neurotoxic effects in the CNS (Bredt \& Snyder, 1992; Vincent \& Hope, 1992; Pannu \& Singh, 2006). NO from different cellular sources functions as a neurotransmitter and also promotes neuronal survival and growth under low concentrations (Dimmeler \& Zeiher, 1999; Xiong et al., 1999). However, in high concentrations, it may exert toxic effects leading neurons to death (Bao \& Liu, 2002; Shibata \& Kobayashi, 2008). NADPH-d had been detected in a subpopulation of neurons in the CNS and myentric plexus (Bredt et al., 1990). Also NADPH-d expression in the aged lumbosacral spinal cord has been reported. Changes in the neurochemical properties of NADPH-d after spinal cord injury may be medicated by pathological changes in the target organs and/or spinal cord (Tan et al., 2006). These results demonstrate that expression of NOS in the dorsal horn of the present study under the non-stressed condition without RKJI may serve for neuroprotective effects, that is, serve as part of a defense mechanism of neuron and of their subsequent recovery with the restoration of muscle function. Expression of NADPH-d in the dorsal horn also may induce by NOS having neuroprotective effects. However, function of NADPH-d and NO in the dorsal horn of the lumbosacral spinal cord still remains speculative. NADPH-d activity has been used as a maker for NOS in neurons (Young et al., 1997). It has been argued that NADPH-d activity in the fixed brain is used as a marker for nNOS, and NADPH-d and nNOS are actually the same enzyme (Dawson et al., 1991). In contrast with the former studies, there is evidence that NADPH-d activity is not always a specific histochemical marker for the NO and these activities are not always co-localized (Kemp et al., 1988; Bredt et al., 1991; Matsumoto et al., 1993; Tracey et al., 1993; Doone et al., 1999). Tracey et al. (1993) suggested that NOS represents only a fraction of the total cellular NADPH-d activity and that these activities are not always co-localized. In the present study, there were a difference in expression of NADPH-d and NO in the dorsal horn of the lumbosacral spinal cord according to the duration of release after RKJI and the presence or absence of joint mobilization. In case of NADPH-d in the dorsal horn, nonspecific activity was seen in the $8 \mathrm{I}-2 \mathrm{M}$ group and non-immobilization control, low level activity was seen in the $8 \mathrm{I}-2 \mathrm{~N}$ and $4 \mathrm{I}-2 \mathrm{M}$ groups and high level activity was seen in the 4I-2N group. In case of NOS in the dorsal horn, nonspecific activity was seen in the 8I-2M group and non-immobilization control, high level activity was seen in the $8 \mathrm{I}-2 \mathrm{~N}$ group and low level activity were seen in the $4 \mathrm{I}-2 \mathrm{M}$ and $4 \mathrm{I}-2 \mathrm{~N}$ groups. Thus, NADPH-d histochemistry and NOS immunohistochemistry do not absolutely label the same neuron population.

The present study demonstrated that joint mobilization effective against the knee joint problems having progressive degeneration by the knee joint immobilization. According to our data, groups with joint mobilization, 8I-2M and 4I-2M had nonspecific or low level activity of NADPH-d and NOS in the dorsal horn of the lumbosacral spinal cord than groups without joint mobilization, $8 \mathrm{I}-2 \mathrm{~N}$ and $4 \mathrm{I}-2 \mathrm{~N}$. Especially the $8 \mathrm{I}-2 \mathrm{M}$ group as the non-immobilization control had only nonspecific activity of NADPH-d and NOS in the dorsal horn of the lumbosacral spinal cord. From the above results, joint mobilization was effective in RKJI and more effective against a long-term RKJI than a short-term RKJI. Thus, expression of NADPH-d and NOS in the dorsal horn of the lumbosacral spinal cord could be regarded as one of estimated instruments for effects of joint mobilization. Similar results were obtained in measured value of area in the femoral muscular fibers. Although values of area in the femoral muscular fibers of 4I$2 \mathrm{M}$ group were not distinguished from those of $4 \mathrm{I}-2 \mathrm{~N}$ group, significantly large values of area in the femoral muscular fibers of $8 \mathrm{I}-2 \mathrm{M}$ group were not only distinguished from those of $8 \mathrm{I}-2 \mathrm{~N}$ group but also those of non-immobilization control. These results demonstrate that measured value of area in the femoral muscular fibers showed effects of joint mobilization in RKJI and more effective against a long-term RKJI than a short-term RKJI. However, in observation of ultrastructures of the femoral nerves, all experimental groups had partial demyelination and condensed clumps in axon, and the extent of modification and morphological characteristics in axon and myelin sheath are similar to all experimental groups. So that, ultrastructures of the femoral nerves is no difference according to the duration of joint mobilization.

\section{CONCLUSIONS}

The present study demonstrates that joint mobilization is effective against knee joint problems having a progressive degeneration by the knee joint immobilization. Especially joint mobilization is more effective against a long-term immobilization than a short-term immobilization. Expression of NADPH-d and NOS in the dorsal horn of the lumbosacral spinal cord could be regarded as one of estimated instruments for effects of joint mobilization.

\section{CONFLICT OF INTEREST}

No potential conflict of interest relevant to this article was reported. 


\section{REFERENCES}

Bao F and Liu D (2002) Peroxynitrite generated in the rap spinal cord induces neuron death and neurological deficits. Neuroscience 115, 839-849.

Bredt D S, Hwang P M, Glatt C E, Lowenstain C, Reed R R, and Snyder S H (1991) Cloned and expressed nitric oxide synthase structurally resembles cytochrome P-450 reductase. Nature 351, 714-718.

Bredt D S, Hwang P M, and Snyder S H (1990) Localization of nitric oxide synthase indicating a neural role for nitric oxide. Nature 347, 768-770.

Bredt D S and Snyder S H (1992) Nitric oxide, a novel neuronal messenger. Neuron 8, 3-11.

Dawson T M, Bredt D S, Fotuhi M, Hwang P M, and Snyder S H (1991) Nitric oxide synthase and neuronal NADPH diaphorase are identical in brain and peripheral tissue. Proc. Natl. Acad. Sci. USA. 88, 77977801.

Dimmeler S and Zeiher A M (1999) Nitric oxide: an endothelial cell survival factor. Cell Death Differ. 6, 964-968.

Doone V G, Pelissier N, Manchester T, and Vizzard A M (1999) Distribution of NADPH-d and nNOS-IR in the thoracolumbar and sacrococcygeal spinal cord of the guinea pig. J. Auton. Nerv. Syst. 77, 98-113.

Dorn T, Schaible H G, and Schmidt R F (1991) Response properties of thick myelinated group II afferents in the medial articular nerve of normal and inflamed knee joint of the cat. Somatosens. Motor Res. 8, 127-136.

Dougherty P M, Sluka K A, Sorkin L S, Westlund K N, and Willis W D (1992) Neural changes in acute arthritis in monkeys, I. Parallel enhancement of responses of spinothalamic tract neurons to mechanical stimulation and excitatory amino acids. Brain Res. Rev. 171, 1-13.

Fuglsang-Frederiksen A and Scheel U (1978) Transient decrease in number of motor units after immobilization in man. J. Neurol. Neurosurg. Psychiatry 41, 924-929.

Gardner E (1995) The distribution and termination of nerves in the knee joint of the cat. J. Comp. Neurol. 80, 11-32.

Gonzalez M F, Sharp F R, and Sagar S M (1987) Axotomy increases $\mathrm{NADPH}$ - diaphorase staining in rat vagal motor neurons. Brain Res. Bull. 18, 417-427.

Good P F, Hsu A, Werner P, Perl D P, and Olanow C W (1998) Protein nitration in Parkinson's disease. J. Neuropathol. Exp. Neurol. 57, 338-342.

Hama A T and Sagen J (1994) Induction of spinal NADPH-diaphorase by nerve injury is attenuated by adrenal medullary transplants. Brain Res. 640, 345-351.

He X and Dishman V (2009) Spinal motor neuronal degeneration after knee joint immobilization in the guinea pig. J. Manipulative Physiol. Ther. 33, 328-337.

He X H, Rose J L, and Zhang N (2009) Extrinsic and intrinsic innervations of the guinea-pig knee joint: toward an animal model for manipulative therapy. J. Manipulative Physiol. Ther. 32, 223-231.

Hee X H, Tay S S W, and Ling E A (1997) Expression of NADPH-diaphorase and nitric oxide synthase in lumbosacral motorneurons after knee joint immobilization in the guinea pig. J. Anat. 191, 603-610.

Hildebrand C, Öqvist G, Brax L, and Tuisku F (1991) Anatomy of the rat knee joint and fiber composition of a major articular nerve. Anat. Rec. 229, 545-555.
Hoskins W, McHardy A, Pollard H, Windsham R, and Onley R (2001) Chiropractic treatment of lower extremity conditions: a literature review. J. Manipulative Physiol. Ther. 29, 658-671.

Ischiropoulos H and Beckman J S (2003) Oxidative stress and nitration in neurodegeneration: cause, effect, or association? J. Clin. Invest. 111, 163-169.

Kanemura N, Kobayashi R, and Kajihara H (2002) Changes of mechanoreceptor in anterior cruciate ligament with hindlimb suspension rats. $J$. Phys. Ther. Sci. 14, 27-32.

Kemp M C, Kuonen D R, Sutton A, and Roberts P J (1988) Rat brain NADPH-dependent diaphorase: a possible relationship to cytochrome P450 reductase. Biochem. Pharmacol. 37, 3063-3070.

Kennedy J C, Alexander I J, and Hayes K C (1982) Nerve supply of the human knee joint and its functional importance. Am. J. Sports Med. 10, 329-335.

Lee S H, Wang S C, and Shen C L (1991) Innervation of the knee joint in the rabbit and the Formosan rock-monkey (Macaca Cyclopis): a retrograde HRP study. Proc. Natl. Sci. Coune. Repub. China B 15, 171-177.

Lei S Z, Pan Z H, Aggarwal S K, Chen H S, Hartman J, and Sucher N J (1992) Effect of nitric oxide production on the redox modulatory site of the NMDA receptor-channel complex. Neuron 8, 1087-1099.

Li Y, Wu W, Schinco F P, and Goode G E (1993) Sciatic nerve transaction causes expression of nitric oxide synthase (NOS) and death of spinal motoneurons in newborn and earlier postnatal rats. Soc. Neurosci. Abstr. 19, 440 .

Martin L J, Chen K, and Liu Z (2005) Adult motor neuron apoptosis is mediated by nitric oxide and fas death receptor linked by DNA damage and p53 activation. J. Neuroscience 25, 6449-6459.

Matsumoto T, Nakane M, Pollock J S, Kun J E, and Forstermann U (1993) A correlation between soluble brain nitric oxide synthase and NADPH-diaphorase activity is only seen after exposure of the tissue to fixative. Neurosci. Lett. 155, 61-64.

Michinaka Y, Yamamoto H, Morisawa T, and Uemura H (1997) Effect of immobilization of the knee joint on mechanoreceptors in anterior cruciate ligament of the rabbit. J. Orthop. Sci. 2, 259-265.

Nelson C F, Lawernce D J, Triano J J, Bronfort G, Perle S M, and Metz R D (2005) Chiropractic as spine care: a model for the profession. Chiropr. Osteopath. 13, 9.

Pannu R and Singh I (2006) Pharmacological strategies for the regulation of inducible nitric oxide synthase: neurodegenerative versus neuroprotective mechanisms. Neurochem. Int. 49, 170-182.

Shibata N and Kobayashi M (2008) The role for oxidative stress in neurodegenerative diseases. Brain Nerve 60, 157-170.

Sung Y H, Lee S H, Sung J K, Han J H, Kim H, Kim C J, and Kang J M (2010) Preconditioning of isoflurane on spinal cord ischemia can increase the number of inducible nitric oxide synthase expressing motor neurons in rat. Korean Anesthesiol. 58, 70-75.

Tabner B J, Turnbull S, El-Agnaf O M, and Allsop D (2002) Formation of hydrogen peroxide and hydroxyl radicals from $A(\beta)$ and $\alpha$-synuclein as a possible mechanism of cell death in Alzheimer's disease and Parkinson's disease. Free Radic. Biol. Med. 32, 1076-1083.

Tan H, He J, Wang S, Hirata K, Yang Z, Kuraoka A, and Kawabuchi M (2006) Age-related NADPH-diaphorase positive bodies in the lumbosacral 
spinal cord of aged rats. Arch. Histol. Cytol. 69, 297-310.

Tracey W R, Nakane M, Pollock J S, and Forstermann U (1993) Nitric oxide synthases in neuronal cells, macrophages and endothelium are NADPH diaphorase, but represent only a fraction of total cellular NADPH diaphorase activity. Biochem. Biophys. Res. Commun. 195, 1035-1040.

Vincent S R and Hope T (1992) Neurons that say NO. Trends Neurosci. 15, 108-113.

Wu W, Han K, Li L, and Schinco F P (1994) Implantation of PNS graft inhibits the induction of neuronal nitric oxide synthase and enhances the survival of spinal motoneurons following root avulsion. Exp. Neurol. 129, 335-339.

Wu W and Li L (1993) Inhibition of nitric oxide synthase reduces motoneuron death due to spinal root avulsion. Neurosci. Lett. 153, 121124.
Xiaohua H E, Jeames L R, Niu Z, and Hong S P (2008) Extrinsic and intrinsic innervation of the guinea pig knee joint: toward an animal model for manipulative therapy. J. Manipulative Phys. Ther. 32, 223231.

Xiong H, Yamada K, Han D, Nabeshima T, Enikolopov G, Garnahan J, and Nawa $H$ (1999) Mutual regulation between the intercellular messenger nitric oxide and brain-derived neurothrophic factor in rodent neocortical neurons. Eur. J. Neurosci. 11, 1567-1576.

Young H M, O'Brien A J, Furness J B, Ciampoli D, Hardwick J P, McCabe T J, Narayanasami R, Masters B S, and Tracey W R (1997) Relationships between NADPH diaphorase staining and neuronal, endothelial, and inducible nitric oxide synthase and cytochrome p450 reductase immunoreactivities in guinea-pig tissues. Histochem. Cell Biol. 107, 19-29. 